Journal of Law and Economics, 41, 727-736, October 1998.

\title{
The Efficiency of the FCC Spectrum Auctions
}

\author{
Peter Cramton*
}

University of Maryland

\begin{abstract}
From July 1994 to July 1996, the Federal Communications Commission (FCC) conducted nine spectrum auctions, raising about $\$ 20$ billion for the U.S. Treasury. The auctions assigned thousands of licenses to hundreds of firms. Were the auctions efficient? Did they award the licenses to the firms best able to turn the spectrum into valuable services for consumers? There is substantial evidence that the FCC's simultaneous ascending auction worked well. It raised large revenues. It revealed critical information in the process of bidding and gave bidders the flexibility to adjust strategies in response to new information. As a result, similar licenses sold for similar prices, and bidders were able to piece together sensible sets of licenses.
\end{abstract}

JEL No.: D44 (Auctions), L96 (Telecommunications)

Keywords: Auctions, Multiple-Item Auctions, Spectrum Auctions

Send comments to:

Professor Peter Cramton

Department of Economics

University of Maryland

College Park, MD 20742-7211

cramton@umd.edu

(301) 405-6987

*I am grateful to the National Science Foundation for funding. I served as an auction advisor to the Federal Communications Commission and several firms (PageNet, MCI, Pocket Communications, and CD Radio) in various auctions. The views expressed are my own. 


\title{
The Efficiency of the FCC Spectrum Auctions
}

\author{
Peter Cramton
}

From July 1994 to July 1996, the Federal Communications Commission (FCC) conducted nine spectrum auctions, raising about $\$ 20$ billion for the U.S. Treasury. The auctions assigned thousands of licenses to hundreds of firms. These firms are now in the process of creating the next generation of wireless communication services. The questions addressed in this note are: Were the auctions efficient? Did they award the licenses to the firms best able to turn the spectrum into valuable services for consumers?

In addressing these questions, I focus on the narrow question of license assignment. Assignment is the second step in the process of utilizing spectrum. The first step is the allocation of the spectrum for licensing. The allocation defines the license (the frequency band, the geographic area, the time period, and the restrictions on use). I focus on assignment, since that is what the FCC spectrum auctions were asked to do. More general auctions that determine aspects of the allocation, such as band plans, have yet to be implemented.

Why should we care about auction efficiency? If resale is allowed, will not postauction transactions fix any assignment inefficiencies? The answer is "yes" in a Coasean world without transaction costs. However, transaction costs are not zero. Postauction transactions are often made difficult by strategic behavior between parties with private information and market power. The experience with the cellular lotteries is a case in point. It took a decade of negotiations and private auctions for the eventual service providers to acquire desirable packages of licenses from the lottery winners. Efficient auctions are possible before assignments are made but may become impossible after an initial assignment. The problem is that the license holder exercises its substantial market power in the resale of the license. ${ }^{1}$ For this reason, it is important to get the assignment right the first time.

All but two of the FCC auctions have used a simultaneous ascending design in which groups of related licenses are auctioned simultaneously over many rounds of bidding. In each round, bidders submit new higher bids on any of the licenses they desire, bumping the standing high bidder. The auction ends when a round passes without any bidding; that is, no bidder is willing to raise the price on any license. This design, proposed by Preston McAfee, Paul Milgrom, and Robert Wilson, is the natural extension of

\footnotetext{
${ }^{1}$ Peter Cramton, Robert Gibbons \& Paul Klemperer, Dissolving a Partnership Efficiently, 55 Econometrica 615 (1987).
} 
the English auction to multiple related goods. ${ }^{2}$ Its advantage over a sequence of English auctions is that it gives the bidders more flexibility in moving among license packages as prices change. As one license gets bid up, a bidder can shift to an alternative that represents a better value. In this way, bidders are able to arbitrage across substitutable licenses. Moreover, they can build packages of complementary licenses using the information revealed in the process of bidding. Here I examine whether these potential advantages were realized.

The analysis is speculative. Since I do not observe the bidders actual valuations, it is impossible to say exactly how efficient the auctions were. Nonetheless, there is substantial evidence that the auctions were successful. I present this evidence and then identify the problems inherent in the auctions that suggest possible inefficiencies.

\section{Evidence of Success}

Revenue is a first sign of success. Auction revenues have been substantial, breaking $\$ 20$ billion in the first 2 years. ${ }^{3}$ Revenues have exceeded industry and government estimates. ${ }^{4}$ The simultaneous ascending auction may be partially responsible for the large revenues. By revealing information in the auction process, the winner's curse is reduced, and the bidders can bid more aggressively. ${ }^{5}$ Also, revenues may increase to the extent the design enables bidders to piece together more efficient packages of licenses.

Revenue maximization and efficiency are closely aligned goals. Indeed, in ex ante symmetric settings, the seller's expected revenue is maximized by assigning the goods to those with the highest values. ${ }^{6}$ High prices are consistent with an efficient auction since only bidders with high values are willing to pay high prices. Moreover, efficiency-minded governments should care about the revenues raised at auction since auction revenues are less distortionary than the principal source of government revenues-taxation. Economists estimate that the welfare loss from increasing taxes in the United States

\footnotetext{
${ }^{2}$ See McAfee, R. Preston, Auction Design of Personal Communication Services, attached to Comments of PacTel Corporation in PP Docket No. 93-253 (1993); and Milgrom, Paul \& Robert Wilson, Affidavit of Paul R. Milgrom and Robert B. Wilson, attached to Comments of Pacific Bell and Nevada Bell in PP Docket No. 93-253 (1993).

${ }^{3}$ All auction data are available from the FCC's web site at www.fcc.gov.

${ }^{4}$ An exception is the Wireless Communications Services auction, which began April 15, 1997.

${ }^{5}$ Paul R. Milgrom \& Robert J. Weber, A Theory of Auctions and Competitive Bidding, 50 Econometrica 1089 (1982).

${ }^{6}$ Lawrence M. Ausubel \& Peter Cramton, Demand Reduction and Inefficiency in Multi-Unit Auctions (Working paper, Univ. Maryland 1996).
} 
is in the range of 17-56 cents per dollar of extra revenue raised. ${ }^{7}$ Hence, in designing the auction, the government should be willing to accept some assignment inefficiency if the gain in revenues is sufficiently large.

A second indicator of success is that the auctions tended to generate market prices. Similar items sold for similar prices. In the narrowband auctions, the price differences among similar licenses were at most a few percent and often zero. In the first broadband auction, where two licenses were sold in each market, the prices differed by less than one minimum bid increment in 42 of the 48 markets.

A third indicator of success is the formation of efficient license aggregations. Bidders did appear to piece together sensible license aggregations. This is clearest in the narrowband auctions. In the nationwide narrowband auction, bidders buying multiple bands preferred adjacent bands. The adjacency means that the buffer between bands can be used for transmission, thus increasing capacity. The two bidders that won multiple licenses were successful in buying adjacent bands. In the regional narrowband auction, the aggregation problem was more complicated. Several bidders had nationwide interests, and these bidders would have to piece together a license in each of the five regions, preferably all on the same band, in order to achieve a nationwide market. The bidders were remarkably successful in achieving these aggregations. Four of the six bands sold as nationwide aggregations. Bidders were able to win all five regions within the same band. Even in the two bands that were not sold as nationwide aggregations, bidders winning multiple licenses won geographically adjacent licenses within the same band.

Large aggregations were also formed in the Major Trading Area (MTA) broadband auction. Bidders tended to win the same band when acquiring adjacent licenses. The three bidders with nationwide interests appear to have efficient geographic coverage when one includes their cellular holdings. The footprints of smaller bidders also seem consistent with the bidders' existing infrastructures. In the C-block auction, bidders were able to piece together contiguous footprints, although many bidders were interested in stand-alone markets.

Two studies analyze the MTA and Basic Trading Area (BTA) auction data to see if there is evidence of local synergies. ${ }^{8}$ Consistent with local synergies, these studies find that bidders did pay more when

\footnotetext{
${ }^{7}$ Charles L. Ballard, John B. Shoven, and John Whalley, General Equilibrium Computations of the Marginal Welfare Costs of Taxes in the United States, 75 Am. Econ. Rev. 128 (1985).

${ }^{8}$ Lawrence M. Ausubel, Peter Cramton, R. Preston McAfee \& John McMillan, Synergies in Wireless Telephony: Evidence from the Broadband PCS Auctions 6 J. Econ. \& Mgmt. Strategy 497 (1997); and Patrick S. Moreton \& Pablo T. Spiller, What's in the Air: Interlicense Synergies and Their Impact on the FCC's Broadband PCS License Auctions, 41 J. Law \& Econ. ?? (1998).
} 
competing with a bidder holding neighboring licenses. Hence, bidders did bid for synergistic gains and, judging by the final footprints, often obtained them.

The two essential features of the FCC auction design are (1) the use of multiple rounds, rather than a single sealed bid, and (2) simultaneous, rather than sequential sales. The goal of both of these features is to reveal information and then give the bidders the flexibility to respond to the information. There is substantial evidence that the auction was successful in revealing extensive information. Bidders had good information about both prices and assignments at a point in the auction where they had the flexibility to act on the information. ${ }^{9}$ The probability that a high bidder would eventually win the market was high at the midpoint of each auction. Also the correlation between midauction and final prices was high in each auction. Information about prices and assignments improved throughout each auction and was of high quality before bidders lost the flexibility to move to alternative packages.

The absence of resale also suggests that the auctions were highly efficient. In the first two years, there has been little resale. GTE is the one exception. Shortly after the MTA auction ended, GTE sold its MTA winnings for about what it paid for the licenses. Apparently there was a shift in corporate strategy away from Personal Communication Services (PCS) and toward cellular.

\section{Potential Problems}

Despite the apparent success of these auctions there are several potential problems that stand in the way of an efficient assignment.

Standard auctions at best ensure that the bidder with the highest private value wins, rather than the bidder with the highest social value. Private and social values can diverge in these auctions because the winners will be competing in a marketplace. One collection of winners may lead to a more collusive industry structure. For example, a license may be worth more to an incumbent than a new entrant, simply because of the greater market power the incumbent would enjoy without the new entrant. Recognizing this, the FCC limits the amount of spectrum any one firm can hold in any geographic area. Indeed, the FCC forbids incumbent cellular firms from bidding in their markets. Another example comes from the battle over technology standards in broadband PCS. Supporters of one standard may value a license more highly if it creates a hole in the footprint of a competing standard, putting the competing standard at a competitive disadvantage. This may have been an issue in the fight over Chicago in the C-block auction. Chicago was a major hole in the Global System for Mobile communications (GSM) footprint, but was

\footnotetext{
${ }^{9}$ Peter Cramton, The FCC Spectrum Auctions: An Early Assessment, 6 J. Econ. \& Mgmt. Strategy 431 (1997).
} 
already covered by the Code Division Multiple Access (CDMA) footprint. However, a GSM bidder only got the license after a long fight with the largest CDMA bidder.

A second issue stems from the fact that these are multiple-item auctions. The efficiency results from single-item auctions do not carry forward to the multiple-item setting. In an ascending auction for a single item, each bidder has a dominant strategy of bidding up to its private valuation. Hence, the item always goes to the bidder with the highest value. If, instead, two identical items are being sold in a simultaneous ascending auction, then a bidder has an incentive to stop bidding for the second item before its marginal valuation is reached. Continuing to bid for two items raises the price paid for the first. ${ }^{10}$ As a result, the bidder with the highest value for the second item may be beaten by a bidder demanding just a single unit.

This logic is quite general. In multiunit uniform-price auctions, every equilibrium is inefficient. ${ }^{11}$ Bidders have an incentive to shade their bids for multiple units, and the incentive to shade increases with the quantity being demanded. Hence, large bidders will shade more than small bidders. This differential shading creates an inefficiency. The small bidders will tend to inefficiently win licenses that should be won by the large bidders. The intuition for this result is analogous to why a monopolist's marginal revenue curve lies below its demand curve: bringing more units to market reduces the price paid on all units. In the auction, demanding more units raises the price paid on all units. Hence, the incentive to reduce demand.

To a large extent, the FCC spectrum auctions can be viewed as a uniform-price auction. Certainly, for licenses that are close substitutes, the simultaneous ascending auction has generated near uniform prices for similar items. Hence, large bidders in the spectrum auctions had an incentive to make room for smaller rivals.

Direct evidence of demand reduction was seen in the nationwide narrowband auction. The largest bidder, PageNet, reduced its demand from three of the large licenses to two, at a point when prices were still well below its marginal valuation for the third unit. ${ }^{12}$ PageNet felt that, if it continued to demand a third license, it would drive up the prices on all the others to disadvantageously high levels.

An examination of the bidding in the MTA broadband auction is suggestive that the largest bidders did drop out of certain markets at prices well below plausible values. Although this could be tacit

\footnotetext{
${ }^{10}$ For settings where this effect is strong, see Richard Engelbrecht-Wiggans \& Charles M. Kahn, Multiunit Auctions with Uniform Prices (Working paper, Univ. Illinois 1995).

${ }^{11}$ Ausubel \& Cramton, supra note 6.

${ }^{12}$ I was a member of the PageNet bidding team. See Peter Cramton, Money Out of Thin Air: The Nationwide Narrowband PCS Auction, 4 J. Econ. \& Mgmt. Strategy 267 (1995), for a detailed analysis of this auction.
} 
collusion, demand reduction is another explanation. Individual maximizing behavior would cause large bidders to make room for rivals to keep prices down.

Further evidence of demand reduction comes from the C-block auction. One large bidder defaulted on the down payment, so the FCC reauctioned the licenses. Interestingly, the licenses sold for 3 percent more than in the original auction. Consistent with demand reduction, NextWave, the largest winner in the C-block auction, bought 60 percent of the reauctioned spectrum. This occurred despite the fact that NextWave was not the second-highest bidder on any of these licenses in the original auction. NextWave was able to bid aggressively in the reauction, knowing that its bidding would have no affect on prices in the original auction.

In auctions for identical items, the inefficiencies of demand reduction can be eliminated with a Vickrey auction. Alternatively, one can use Lawrence Ausubel's ascending implementation of the static Vickrey auction, which has the additional advantages of an ascending-bid design. ${ }^{13}$ However, the spectrum auctions were not for identical items, so Vickrey-type mechanisms were not practical.

There are good reasons to think that any inefficiencies caused by demand reduction in the FCC spectrum auctions are overstated. Demand reduction favors small bidders. Hence, small bidders, having less of an incentive to reduce demand, are able to win licenses they might otherwise not get. Demand reduction, then, fosters competition in the auction by encouraging the participation of small bidders. Perhaps more important, demand reduction may increase competition in the market for wireless services by increasing the number of competing firms.

The FCC, as mandated by Congress, has taken more direct steps to increase the number and diversity of winning firms. One-third of the broadband PCS spectrum has been set aside to small businesses. Preferences, both installment payments and bidding credits, also have been given to designated bidders in the other auctions. One might think that these set asides and preferences would be a prominent source of inefficiency. They let small firms win licenses that might otherwise go to large firms with higher values. However, the auction experience of the first 2 years suggests that the inefficiencies from preferences are small or even negative. In the regional narrowband auction, there is strong evidence that preferences to firms controlled by women or minorities raised revenues. ${ }^{14}$ The preferences stimulated competition, forcing the large firms to pay more than they otherwise would. In the C-block broadband auction, which was a set aside for small businesses, competition was so intense that it resulted in prices that were about

\footnotetext{
${ }^{13}$ Lawrence M. Ausubel, An Efficient Ascending-Bid Auction for Multiple Objects (Working paper, Univ. Maryland 1997).

${ }^{14}$ Ian Ayres \& Peter Cramton, Pursuing Deficit Reduction through Diversity: A Case Study of How Affirmative Action at the FCC Increased Auction Competition, 48 Stanford L. Rev. 401 (1996).
} 
80 percent higher than in the earlier MTA auction. ${ }^{15}$ Revenues were certainly stimulated by the preferences to the small firms. Given the dramatic increase in revenues, it is hard to imagine that the assignment of these licenses to small firms involved substantial inefficiencies. These small firms expressed valuations well in excess of what the big firms paid in the prior auction. Moreover, even if the small firms have lower values, the entrance of these small firms is likely to stimulate competition in the market for wireless services.

Another source of inefficiency in the spectrum auctions comes from the difficulties firms may have in piecing together efficient sets of licenses. The ability to form efficient aggregations is greatly enhanced by the excellent information about prices and assignments that is revealed in the auction process. Nonetheless, bidders may be hesitant to bid for synergistic gains they are unlikely to achieve. This exposure problem may lead to a failure to obtain efficient synergies. Similarly, bidders may bid for a synergistic gain, only to find they are inefficiently stuck with some individual licenses that do not make sense without others. Mark Bykowsky, Robert Cull, and John Ledyard emphasize this potential problem and recommend package bidding - being able to bid on a collection of licenses, rather than just on individual licenses. ${ }^{16}$ Although I agree that package bidding may be a good idea in settings where synergies are both strong and varied among the bidders, I do not think that the early spectrum auctions fit this case. Bidders in the narrowband auctions had little difficulty in forming efficient aggregations. In the MTA broadband auction, it appears that the individual markets were sufficiently large to capture most local synergies.

The C-block broadband auction provided the greatest challenge to bidders since the BTA licenses were only about one-tenth the size of the MTA licenses and competition was much more intense. BTAlevel synergies were certainly more important than the MTA-level synergies. However, I do not believe that the exposure problem stifled bidding or prevented firms from forming efficient aggregations. Early in the auction, competition was sufficient that it was easy to move from one package to another. When this was difficult, bidders would focus their bidding in the major markets that were key to synergistic gains. For example, Chicago is a key market in obtaining a strong Midwest presence. Hence, the fight over Chicago was resolved before the winning firm would bid seriously for the smaller complementary licenses neighboring Chicago. As a result of this strategy, major markets tended to receive final bids before the smaller markets.

\footnotetext{
15 The 80 percent figure comes after netting out the 25 percent bidding credit and an additional credit of about 30 percent derived from the value of the favorable installment payments.

${ }^{16}$ Mark M. Bykowsky, Robert J. Cull, and John O. Ledyard, Mutually Destructive Bidding: The FCC Auction Design Problem (Working paper, California Inst. Technology 1995).
} 
Several firms did acquire clusters of adjacent licenses in the C-block auction. However, the bidding of the largest bidder, NextWave, suggests that local synergies were not large. NextWave pursued a strategy of acquiring major markets around the United States. Spending nearly $\$ 5$ billion, it had the resources to instead acquire large contiguous clusters in a few parts of the country but chose not to do so. NextWave's strategy would not make sense if local synergies were large at the BTA level.

A potentially serious inefficiency in the C-block auction was speculative bidding caused by overly attractive installment payment terms. Bidders only had to put down 5 percent of their bids at the end of the auction, a second 5 percent at the time of license award, and then quarterly installment payments at the 10-year Treasury rate with interest-only payments for the first 6 years. These attractive terms favor bidders that are speculating in spectrum. If prices go up, the speculators do well; if prices fall, the speculators can walk away from their down payments. Indeed, spectrum prices did fall after the C-block auction, and most of the large bidders in the C-block auction defaulted on the payments. As a result of this experience, the FCC no longer offers installment payments. Bids must be paid in full when the licenses are awarded.

A final source of inefficiency comes, not from bad assignments, but from delayed assignments. Each month of delay means a loss of consumer surplus. The simultaneous ascending auctions took a significant amount of time to conduct. Relatively simple auctions, like the nationwide narrowband auction, were done in a week. However, the more complex auctions with hundreds of bidders and licenses (the C-block, Multipoint Distribution Service (MDS), and Specialized Mobile Radio (SMR) auctions) took about 80 bidding days.

The simultaneous ascending auction has a number of parameters (minimum bid increments, activity requirements, and rounds per day) that let the FCC control the pace of the auction. The parameters are adjusted during the auction to balance the goals of a timely and desirable assignment. The bidders need time to adjust strategies in light of information revealed in the bidding. Too much haste may lead to bidder error and inefficient assignments. Time also may be needed for bidders to line up additional capital if prices are higher than expected. Certainly, these spectrum auctions could have been conducted more quickly, but probably not without reducing the efficiency of the assignment.

\section{Conclusion}

Any auction would look good relative to the FCC's past experience with comparative hearings and lotteries. Hence, it is remarkable that the FCC chose an innovative and untested design to auction the spectrum. Fortunately, there is now substantial evidence that the simultaneous ascending auction worked well. It raised large revenues. It revealed critical information in the process of bidding and gave bidders 
the flexibility to adjust strategies in response to new information. As a result, similar licenses sold for similar prices, and bidders were able to piece together sensible sets of licenses.

The setting of the spectrum auctions is too complex to guarantee full efficiency. Bidders with the highest private values may not have the highest social values. To keep prices low, large bidders may reduce demand, inefficiently making room for smaller rivals. Preferences for designated bidders may distort assignments. And bidders may hesitate to bid for synergistic combinations for fear of not obtaining the synergies. Nonetheless, an examination of the bidding suggests that these problems, although present, probably did not lead to large inefficiencies. Moreover, the cures to these problems have side-effects that may be worse than the disease.

The spectrum auctions are a major step toward creating a market for spectrum. The greatest room for improvement lies, not in the assignment of licenses, but in the allocation process. Some allocations, like PCS, allow flexible use, but others, such as broadcasting, do not. Further steps need to be taken to assure that market forces, not political lobbying, determine spectrum use.

\section{References}

Ausubel, Lawrence M., An Efficient Ascending-Bid Auction for Multiple Objects (Working paper, Univ. Maryland 1997).

Ausubel, Lawrence M. \& Peter Cramton, Demand Reduction and Inefficiency in Multi-Unit Auctions (Working paper, Univ. Maryland 1996).

Ausubel, Lawrence M., Peter Cramton, R. Preston McAfee \& John McMillan, Synergies in Wireless Telephony: Evidence from the Broadband PCS Auctions, 6 J. Econ. \& Mgmt. Strategy 497-527 (1997).

Ayres, Ian \& Peter Cramton, Deficit Reduction through Diversity: A Case Study of How Affirmative Action at the FCC Increased Auction Competition, 48 Stanford L.Rev. 761-815 (1996).

Ballard, Charles L., John B. Shoven \& John Whalley, General Equilibrium Computations of the Marginal Welfare Costs of Taxes in the United States, 75 Am. Econ. Rev. 128-138 (1985).

Bykowsky, Mark M., Robert J. Cull \& John O. Ledyard, Mutually Destructive Bidding: The FCC Auction Design Problem, (Working paper, California Inst. Technology 1995).

Cramton, Peter, Money Out of Thin Air: The Nationwide Narrowband PCS Auction, 4 J. Econ. \& Mgmt. Strategy 267-343 (1995).

Cramton, Peter, The FCC Spectrum Auctions: An Early Assessment, 6 J. Econ. \& Mgmt. Strategy 431-495 (1997).

Cramton, Peter, Robert Gibbons \& Paul Klemperer, Dissolving a Partnership Efficiently, 55 Econometrica 615-632 (1987).

Engelbrecht-Wiggans, Richard \& Charles M. Kahn, Multi-Unit Auctions with Uniform Prices (Working paper, Univ. Illinois 1995).

McAfee, R. Preston, Auction Design of Personal Communication Services, attached to Comments of PacTel Corporation in PP Docket No. 93-253 (1993).

Milgrom, Paul \& Robert J. Weber, A Theory of Auctions and Competitive Bidding, 50 Econometrica 1089-1122 (1982). 
Milgrom, Paul \& Robert Wilson, Affidavit of Paul R. Milgrom and Robert B. Wilson, attached to Comments of Pacific Bell and Nevada Bell in PP Docket No. 93-253 (1993).

Moreton, Patrick S. \& Pablo T. Spiller, What's in the Air? Interlicense Synergies and Their Impact on the FCC's Broadband PCS License Auctions, 41 J. Law \& Econ. ?? (1998). 